\title{
Metallographic Characterization of Some New Bioactive Implant Titanium Alloys
}

\author{
J.C.Mirza Rosca ${ }^{*}$, J. Rodriguez Castro* and A. Santana López* \\ * Dept. of Mechanical Engineering, University of Las Palmas de Gran Canaria, Tafira, 35017, Spain
}

Titanium alloys possess attractive properties for biomedical applications where the most important factor is biocompatibility. Between the titanium alloys, the Ti-6Al-4V has been successfully applied for biomedical applications [1], because it possesses sufficient strength and ductility for use as human body implants [2].

Aluminium is an alpha phase stabilizer and Vanadium a beta phase stabilizer, in consequence the titanium alloys with $\mathrm{Al}$ and $\mathrm{V}$ have a two-phase alpha-beta structure. The alpha-beta alloys can be mechanically processed and heat-treated to obtain improved mechanical properties. Futher studies have shown that the release of both $\mathrm{Al}$ and $\mathrm{V}$ ions from the alloy might cause long-term health problems, such as osteomalacia, neuropathy and Alzheimer diseases [3,4]. V presence can be associated with potential cytotoxic effects and adverse tissue reactions and Al produces potential neurological disorders. For this reason, recently, other alloys have been developed to decrease the aluminium concentration (and one of these is Ti-5Al-4V) or to replace vanadium (and one of these is Ti-6Al-3.5Fe). The iron is also beta-phase stabilizer and the resulted alloy has a two-phase alphabeta structure with added advantage of nontoxicity.

It is well known that surface sensitive properties like corrosion and hardness are dependent on the chemical composition of the surface. In this paper $\mathrm{Ti}$, Ti-5 Al-4V and $\mathrm{Ti}-6 \mathrm{Al}-3.5 \mathrm{Fe}$ with the composition presented in the Table 1 were evaluated; the microstructure and microhardness were determined.

From metallographic photos (Fig.1) can be observed that both titanium alloys, Ti-5Al-4V and Ti6Al-4Fe have an alpha-beta structure. Aluminium is an alpha phase stabilizer while $\mathrm{V}$ and $\mathrm{Fe}$ are beta phase stabilizers. The beta phase appears dark and the alpha phase light. Alpha phase was the dominant phase in these alloys.

From Vickers microhardness measurements can be concluded that the alloys formed a hard layer on their surface which greatly improves their wear resistance in comparation with titanium. As the load increases, the values of microhardness are increasing (the layer became more compact). With a load of 200 grams it can be seen that the microhardness is decreasing which mean that the indenter reach the base metal. From the corresponding depth of penetration, it was found that passive film on the implant surface has a two-layer structure: a thin barrier-type inner layer (about $3 \mu$ ) and a porous outer layer (about $1.5 \mu$ ).

The proposed model for the passive layer formed on the surface of the implants, deduced from the metalographical observations and microhardness measurements is shown in figure 2 . The results were confirmed by mechanical approach, in terms of two-layer model of the oxide film, consisting of a thin barrier type inner layer and a porous outer layer. The pronounced porous outer layer is 
expected to facilitate the incorporation of mineral ions and to improve the resistance to electrochemical corrosion over the potential of relevance for implant conditions.

References

[1] H.A. Luckey, F. Kubli Jr (Eds.), Titanium alloys in Surgical Implants, ASTM Publication STP 796-800, Philadelphia, (1983).

[2] J. Mathew Donachie Jr., Titanium: a Technical Guide, $2^{\text {nd }}$ ed., ASM International, (2000).

[3] J. Yu, Z.J. Zhao and L.X. Li. Corros. Sci. 35, (1993) 587.

[4] S. Rao, T. Ushida, T. Tateishi, S. Okasaki, S. Asao, Bio-med Mater. Eng, 6, (1996), 79.

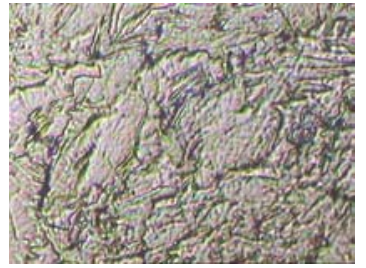

a)

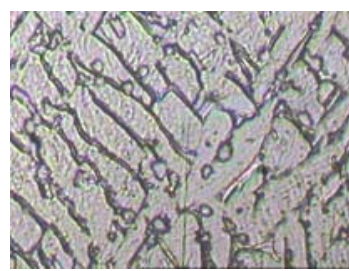

b)

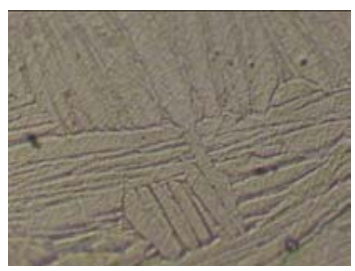

c)

Fig.1. Microscopically aspects of the samples surfaces: a) Ti; b) Ti-5Al-4V and c) Ti-6Al-4Fe

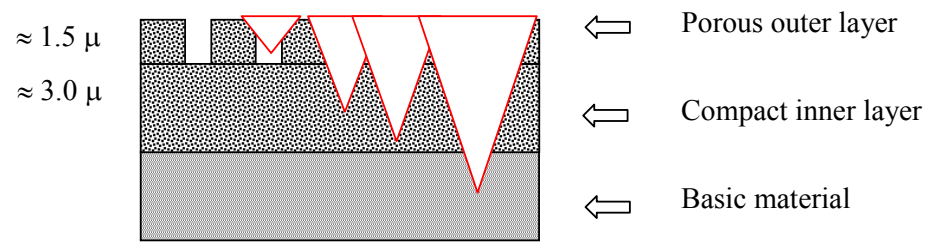

I able I. Composition of the studied implant material

\begin{tabular}{ccccccccc}
\hline \multirow{2}{*}{ Type } & \multicolumn{7}{c}{ Percent weight } \\
\cline { 2 - 9 } & $\mathrm{Al}$ & $\mathrm{Fe}$ & $\mathrm{V}$ & $\mathrm{C}$ & $\mathrm{O}$ & $\mathrm{N}$ & $\mathrm{Ti}$ & \multirow{2}{*}{ Structure } \\
\hline $\mathrm{Ti}$ & 0.005 & 0.095 & - & 0.04 & 0.056 & 0.045 & Rest & - \\
\hline Ti-5Al-4V & 4.88 & 0.021 & 3.72 & 0.048 & 0.175 & 0.0153 & Rest & $\alpha+\beta$ \\
\hline Ti-6Al-4Fe & 6.12 & 3.87 & - & 0.18 & 0.26 & 0.035 & Rest & $\alpha+\beta$ \\
\hline
\end{tabular}

Table 2. Average values of Vickers microhardness obtained with loads of 10, 25, 50 and 200 grams and the corresponding depths.

\begin{tabular}{|c|c|c|c|c|c|c|}
\hline Sample & \multicolumn{2}{|c|}{ Ti } & \multicolumn{2}{|c|}{ Ti-5Al-4V } & \multicolumn{2}{c|}{ Ti-6Al-4Fe } \\
\hline Load $($ grams $)$ & HV & $\mathrm{d}(\mu \mathrm{m})$ & HV & $\mathrm{d}(\mu \mathrm{m})$ & HV & $\mathrm{d}(\mu \mathrm{m})$ \\
\hline 10 & 172 & 1.48 & 332 & 1.07 & 240 & 1.26 \\
\hline 25 & 197 & 2.19 & 450 & 1.45 & 290 & 1.81 \\
\hline 50 & 200 & 3.08 & 452 & 2.05 & 333 & 2.38 \\
\hline 200 & 173 & 6.61 & 416 & 4.26 & 331 & 4.78 \\
\hline
\end{tabular}

